\title{
Objeto de Estudo de Letramento (OEL), um objeto de aprendizagem para auxílio a alfabetização infantil
}

\author{
Kaio Alexandre da Silva1, Luis Filipe de Castro Sampaioㅁ, Saimor Raduan Araújo \\ Souza $^{1}$, Lucas Felipe Alves de Araújoㅁ, Silvio Luiz de Freitas', Marcel Leite Rios ${ }^{1}$ \\ ${ }^{1}$ Instituto Federal de Educação, Ciência e Tecnologia de Rondônia - Campus Porto \\ Velho Calama (IFRO) \\ Caixa Postal 15.064 - 76.820-44 - Porto Velho - RO - Brasil \\ \{luizw12345, saimorraduan, donpizza.if\}@gmail.com, \\ \{Kaio.silva, silvio.freitas, marcel.rios\}eifro.edu.br
}

\begin{abstract}
In recent years the number of people who have mobile devices in Brazil has grown. Through smartphones or tablets anyone can access a vast amount of information anywhere, anytime. In this context, using technology in education enables a new style of learning, less onerous to the student and more practical. Based on the concept of Mobile Learning, the "Object of Study of Literature" (OEL) was developed. Consists of an application and a WEB system. Frequent use of the application enables student learning through the application. The use of the application by the students can be accompanied by the WEB monitoring system.
\end{abstract}

Resumo. Nos últimos anos o número de pessoas que possuem dispositivos móveis no Brasil tem crescido. Através de smartphones ou tablets qualquer pessoa tem a possibilidade de ter acesso a um vasto volume de informações em qualquer lugar, a qualquer hora. Neste contexto, utilizar as tecnologias na educação possibilitam um novo estilo de aprendizado, menos oneroso ao estudante e mais prático. Com base no conceito do Mobile Learning, foi desenvolvido o "Objeto de Estudo de Letramento" (OEL). Constituído por um aplicativo e um sistema WEB. A frequente utilização do aplicativo possibilita o aprendizado do aluno por meio do aplicativo. A utilização do aplicativo pelos alunos pode ser acompanhada pelo sistema de acompanhamento WEB.

\section{Introdução}

De acordo com [Silva and Crenitte 2016], problemas relacionados ao aprendizado da leitura, escrita e pronúncias de palavras podem surgir durante a infância de uma criança. Caso não haja o tratamento dessas disfunções previamente, este individuo poderá ser tornar um analfabeto. Conforme os autores [Terra 2013] e [Soares 1998] uma pessoa é considerada analfabeta quando não consegue extrair informações, por meio da leitura de qualquer tipo de texto, seja ele um texto escrito, comuns no processo chamando de letramento, ou de uma imagem, que segundo [Stokes 2002] é utilizado no chamado de letramento visual. 
Na última década, a rápida difusão de dispositivos móveis na sociedade, trouxe um ambiente com oportunidades de inovações no processo educacional. Segundo [Kampff and et al 2006], qualquer tipo de material que tenha sido desenvolvido para fins educacionais pode ser considerado um objeto de aprendizagem. Sendo assim, softwares que possuam o objetivo de transmitir conhecimento sobre determinado assunto aos seus usuários podem ser considerados um objeto de aprendizagem.

Com a evolução da tecnologia e o surgimento dos smartphones e tablets, nasceu um novo estilo de aprendizagem chamado de Mobile Learning (M-Learning), que segundo [Kukulska-Hulme and Traxler 2005] possibilita ao usuário aprender em qualquer lugar e a qualquer hora. Utilizar tais tecnologias como aliadas ao ensino, auxilia na abertura de oportunidades para o aluno trabalhar a sua criatividade, ao mesmo tempo em que se torna um elemento de motivação e colaboração, uma vez que o processo de aprendizagem da criança se torna atraente, divertido, significativo e auxilia na resolução de problemas que podem ser resolvidos conjuntamente com outras crianças. Neste sentido, o desenvolvimento de um aplicativo móvel para auxiliar no processo do ensino das letras, possibilitando a criança aprender as letras através do processo de assimilação entre os elementos visuais e sonoros introduzidos no aplicativo.

Para que esse aprendizado se torne efetivo é fundamental o acompanhamento de um professor para conduzir o aluno, retirando as dúvidas e dificuldades que ele não consiga superar de forma autônoma. Neste sentido, desenvolver sistemas educacionais que dão suporte ao aprendizado é um desafio a ser superado, visto que aplicações que enfoquem apenas na transmissão de conteúdo podem não ser tão eficazes no processo de aprendizagem do aluno. Com base nisso, utilizar técnicas de recomendações para verificar os índices de aprendizagem dos alunos e demonstrar para o professor os alunos que estão abaixo de um índice estabelecido, fornecendo a estes um acompanhamento personalizado, podem reduzir as dificuldades que normalmente são difíceis de serem identificadas no dia-a-dia. Técnicas de recomendações são geralmente utilizadas em sistemas de vendas e entretenimento. [Garcia and Frozza 2013] define como um sistema que utiliza dados obtidos sobre seus usuários para poder realizar recomendações sobre algo de seu interesse ou necessidade, para isso, as técnicas de recomendações analisam frequentemente os dados obtidos do usuário.

O desenvolvimento do Objeto de Estudo de Letramento (OEL), foi idealizado para realizar a junção do M-Learning e objeto de aprendizagem, complementado por um sistema de monitoramento de tempo real, possibilitando ao professor $o$ acompanhamento da evolução do aluno durante o processo de aprendizado. Para melhor entendimento desse artigo, ele está dividido da seguinte forma: Seção 2 - metodologia, descrevendo o OEL; Seção 3 - conclusões parciais e os trabalhos futuros.

\section{Metodologia}

O processo de alfabetização de uma criança é composto por etapas, sendo uma das primeiras o ensino do alfabeto. Com isso, desenvolvido uma ferramenta lúdica que estimule crianças a aprender e ao mesmo tempo auxiliar os professores no processo de alfabetização. A figura 1 exibe o funcionamento do OEL, demonstrando que ele é formado por um sistema web, uma base de dados, um Web Service e um aplicativo móvel. O sistema web foi nomeado de 'Sistema de Acompanhamento de Desenvolvimento' (SAD). O aplicativo móvel foi desenvolvido para a plataforma 
Android, a base de dados escolhida foi o MySQL e o Web Service foi desenvolvido com a linguagem de programação PHP. A ideia principal do OEL é possibilitar ao professor, o acompanhamento do uso do aplicativo pelos seus alunos, pois é através deste uso que o sistema poderá identificar as dificuldades dos alunos e recomendar ao professor realizar o acompanhamento de forma mais personalizada.

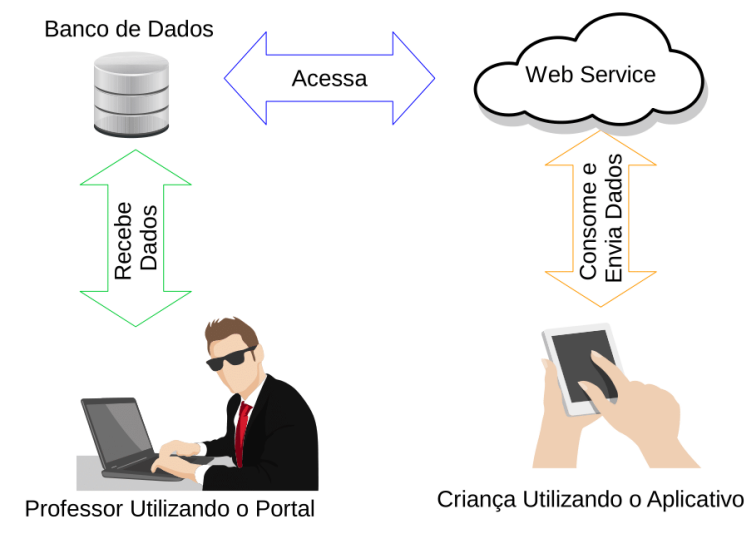

Figura 1. Fluxo de dados

Para isso, o aplicativo foi idealizado para funcionar semelhante as cartilhas utilizadas no processo de alfabetização. Ao entrar no aplicativo é exibido, ao usuário, todas as letras do alfabeto da língua portuguesa. Nesta tela, a criança pode selecionar a letra que deseja aprender. Quando uma letra é selecionada, um áudio contendo a pronúncia desta letra é executado e logo em seguida uma nova tela é apresentada. Tal tela é constituída por imagens associadas à letra selecionada. As imagens constituintes da tela representam as seguintes categorias: alimento, animal, lugar do mundo, nomes masculinos e nomes femininos. Quando uma imagem for selecionada, o áudio é reproduzido descrevendo informações acerca da imagem selecionada. Quando a criança escutar todos os áudios pertencentes à imagem, a atividade proposta com base no conceito de assimilação referente às categorias apresentadas é liberada para execução. Todas as interações realizadas com o aplicativo como por exemplo escolher a letra, são salvas no banco de dados através da utilização do Web Service. O fluxo da utilização do aplicativo é apresentado na figura 2.

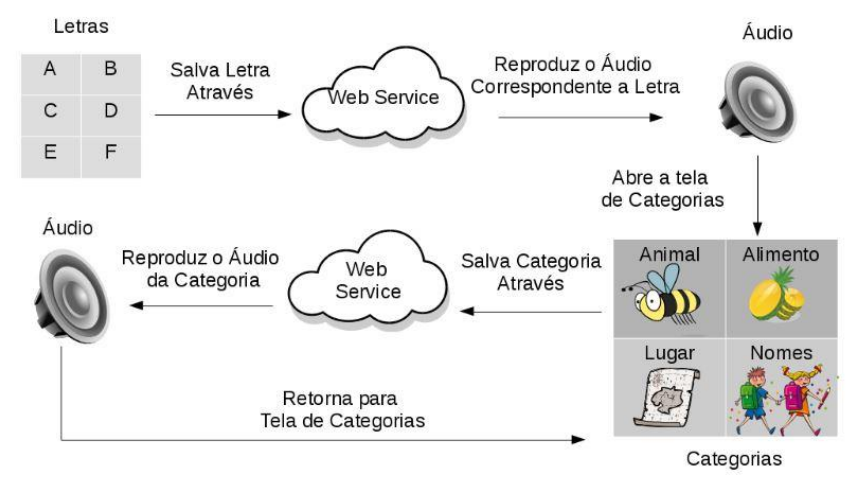

Figura 2. Fluxo de utilização do aplicativo

O SAD utiliza as tecnologias: HTML, CSS, JavaScript e PHP. Nele, o professor pode acompanhar o desempenho de cada um de seus alunos que utilizam o aplicativo 
em forma de gráficos. Além disso, o sistema identifica quais as letras foram as mais e menos acessadas, o histórico do desempenho de cada aluno e recomendações de alunos que estão abaixo da média estabelecida (alunos que serão recomendados para o acompanhamento individual).

O OEL será testado em uma escola da rede pública, em uma turma do primeiro ano do ensino fundamental, a qual será dividida em dois grupos, sendo que só um dos grupos utilizará o aplicativo. A intensão é quantificar a influência do OEL ao longo do aprendizado, para isso uma reunião junto ao professor da turma é realizada a cada quinze dias para saber do andamento dos dois grupos estabelecidos na turma.

\section{Considerações parciais e trabalhos futuros}

A utilização de novas tecnologias no âmbito da educação pode estimular o aprendizado dos alunos, possibilitando trabalhar a sua criatividade, ao mesmo tempo em que se torna um elemento de motivação e colaboração. Isto deixa o processo de aprendizagem mais atraente, divertido e significativo, além disso o aluno cresce com a consciência de um uso mais eficiente das tecnologias que permeiam as nossas vidas.

Como trabalho futuros é proposto o acompanhamento durante o ano junto a turma estipulada, ao final deste período, é previsto a realização de melhorias no OEL para que no ano seguinte se possa realizar um teste mais robusto do uso da tecnologia, ampliando a quantidade de alunos envolvidos no grupo experimental. Todos os dados gerados durante esse período de acompanhamento serão analisados e divulgados através da produção científica. Como resultado final da pesquisa, espera-se deixar o OEL disponível para que qualquer docente do país possa utilizá-lo.

\section{Referências}

Garcia, C. A. and Frozza, R. (2013). Sistema de recomendação de produtos utilizando mineração de dados. Revista Tecno-Lógica, 17:78-90.

Kampff, A. J. C. and et al (2006). Nós no mundo: objeto de aprendizagem voltado para o $1^{\underline{\mathrm{o}}}$ ciclo do ensino fundamental. RENOTE - Revista Novas Tecnologias na Educação, 4:1-10.

Kukulska-Hulme, A. and Traxler, J., editors (2005). Mobile learning: a handbook for educators and trainers. Open and Flexible Learning Series. Routledge, London, UK.

Silva, N. S. M. and Crenitte, P. A. P. (2016). Desempenho de crianças com risco para dificuldade de leitura submetidas a um programa de intervenção. CoDAS, 28:517 525 .

Soares, M., editor (1998). Letramento - Um Tema Em Três Gênero. Autêntica Editora.

Stokes, S. (2002). Visual literacy in teaching and learning: A literature perspective. Elec-tronic Journal for the Integration of Technology in Education.

Terra, M. R. (2013). Letramento letramentos: uma perspectiva sócio-cultural dos usos da escrita. DELTA: Documentação de Estudos em Linguística Teórica e Aplicada, 29:29- 58 . 